\title{
La Orquesta del Conservatorio en el seno de la Universidad Nacional (1917-1929)'
}

\author{
José-Ángel Beristáin-Cardoso
}

\section{RESUMEN}

El artículo tiene como principal objetivo analizar la configuración del campo artístico de los músicos del Conservatorio en el seno de la Universidad Nacional de México, permitiendo develar elementos de pertenencia para el fortalecimiento de su identidad y su proyección en agrupaciones musicales instrumentales como la Orquesta Sinfónica de Alumnos del Conservatorio y la Agrupación Universitaria de Música de Cámara. En este campo, los músicos universitarios siguieron siendo legitimados por el Conservatorio como los destinatarios titulares en su acercamiento a la alta cultura, para llevarla a las capas populares en el contexto del nacionalismo de los gobiernos posrevolucionarios. Se demuestra que el proyecto de fundación del Conservatorio de Música incluyó la creación de una orquesta representativa de alumnos y maestros, y que en la etapa en que se integró esta institución a la Universidad Nacional, la actividad musical se apuntaló con el Plan General de Trabajo del Departamento de Extensión Universitaria, acorde con los principios de difusión, cooperación y servicio social.

Palabras clave: campo, conservatorio, educación, identidad, orquesta, nacionalismo, universidad, México.

José Ángel Beristáin-Cardoso

jose_angelb@hotmail.com Mexicano. Doctor en Historia y Etnohistoria, Escuela Nacional de Antropología e Historia (ENAH), México. Estancia posdoctoral en el Instituto de Investigaciones sobre la Universidad y la Educación (IISUE), de la UNAM, México. Temas de investigación: historia social de la educación artística siglos XIX y XX; patrimonio, instituciones y políticas culturales siglos XIX, XX y XXI.

\footnotetext{
${ }^{1}$ Este artículo se desarrolló durante la estancia posdoctoral "UNAM. Programa de Becas Posdoctorales en la UNAM, becario del Instituto de Investigaciones sobre la Universidad y la Educación, asesorado por las doctoras María Esther Aguirre Lora y Rosalina Ríos Zuñiga, durante el año académico 2017-2018”; dentro del proyecto de investigación "La diáspora de músicos del Conservatorio para la creación de la Facultad de Música de la Universidad. Nuevas miradas al conflicto entre Carlos Chávez y la educación musical universitaria en el contexto del nacionalismo mexicano". Mi agradecimiento al Dr. Leopoldo Rodríguez Morales por sus valiosas sugerencias y comentarios en el Seminario de Investigaciones Posdoctorales del IISUE.
} 


\title{
A Orquestra do Conservatório no seio da Universidade Nacional (1917-1929)
}

\section{RESUMO}

O artigo tem como principal objetivo analisar a configuração do campo artístico dos músicos do Conservatório no seio da Universidade Nacional, permitindo revelar elementos de pertença para o fortalecimento de sua identidade e sua projeção em agrupações musicais instrumentais como a Orquestra Sinfónica de Alunos do Conservatório e a Agrupação Universitária de Música de Câmara. Neste campo, os músicos universitários continuaram sendo legitimados pelo Conservatório como os destinatários titulares em sua aproximação à alta cultura, para levá-la às camadas populares no contexto do nacionalismo dos governos pós-revolucionários. Se demostra que o projeto de fundação do Conservatório de Música incluiu a criação de uma orquestra representativa de alunos e professores, e que na etapa em que se integrou esta instituição à Universidade Nacional, a atividade musical se sustenta no Plano General de Trabalho do Departamento de Extensão Universitária, acorde aos princípios de difusão, cooperação e serviço social.

Palavras chave: ecampo, conservatório, educação, identidade, orquestra, nacionalismo, universidade, México.

\section{The Conservatory Orchestra within the National University (1917-1929)}

\begin{abstract}
The main purpose of this article is to analyze the configuration how the specific features of the artistic field in which performed the musicians of the Conservatory assigned to the National University, allowing to reveal elements of belonging for the strengthening of their identity and their projection in instrumental musical groups such as the Symphonic Orchestra of Students of the Conservatory and the University Group of Chamber Music. In this field, university musicians continued to be legitimized by the Conservatory as the main recipients in their approach to high culture, to bring it to the popular layers in the context of the nationalism displayed by the post-revolutionary governments. It is demonstrated that the project of founding the Conservatory of Music included the creation of an orchestra that could be representative of students and teachers, and that during the period in which this institution was integrated to the National University, the musical activity was underpinned by the General Work Plan of the Department of University Extension, according to the principles of dissemination, cooperation and social service.
\end{abstract}

Key words: field, conservatory, education, identity, orchestra, nationalism, university, Mexico.

Recepción: 12/06/18. Aprobación: 31/10/18. 


\section{Introducción}

El Conservatorio Nacional de Música, desde su creación en 1866, legitimó a los músicos mexicanos que egresaban de sus aulas como "destinatarios titulares" en su acercamiento con la alta cultura. ${ }^{2}$ De esta manera, y considerando que la transmisión escolar siempre ha desempeñado una función de "legitimación" (Bourdieu, 2002b: 83), este refrendo continuó aun cuando el Conservatorio fue insertado en 1917 en el seno de la Universidad Nacional de México (UNM) hasta su separación de la misma en 1929. ${ }^{3}$ Un proceso de separación del Conservatorio y la Universidad que fue permeado por el conflicto de la autonomía de esta última; el maestro Carlos Chávez - entonces director del Conservatorio-, en su particular punto de vista, siempre consideró que dicha autonomía perfilaba el camino a la privatización, puesto que él concebía el camino del éxito en el transitar de lo privado a lo oficial, y no al revés: "México no necesita doctores ni bachilleres en música" (El Universal, 25/VI/1929). ${ }^{4}$

Entre las investigaciones sobre el proceso de autonomía de la UNM destacan las contribuciones de Renate Marsiske (2016: 151), quien logra identificar en la poca claridad sobre las funciones de la Universidad y su relación con el Estado los ingredientes que nutrieron la idea, así como José Woldenberg (2008:
61) quien considera que la Universidad consigue autogobernarse, definir y estructurar sus planes de estudio en una amplia libertad de cátedra, sustentar su independencia ante los poderes públicos, y erigirse como una institución central de la ciencia, la cultura y las artes. La Universidad ha divulgado en sus propios medios de comunicación los argumentos de su autonomía, ${ }^{5}$ como el de una sociedad que requería de una universidad comprometida socialmente, cuyos títulos y virtudes sólo estuvieran basados en sus propios merecimientos y logros (Gaceta UNAM, 19/ XI/2001: I).

El 7 de agosto de 1929, el Consejo Universitario aprobó por unanimidad la creación del Centro Universitario de Estudios Musicales, para el cual se recurrió al reordenamiento del plan de estudios del Conservatorio -institución que pasaría a formar parte del Departamento de Bellas Artes de la Secretaría de Educación Pública-, y se configuró una planta de maestros que impartirían clases gratuitamente en el edificio de Mascarones, nombrándose director interino al maestro Estanislao Mejía (Aguirre, 2015: 88). Finalmente, el 20 de septiembre del mismo año, el abogado José López Lira - Secretario General de la Universidad Nacional - informó al profesor Estanislao Mejía que el Honorable Consejo Universitario, en su sesión del día 11 de

\footnotetext{
${ }^{2}$ Definiremos a la "alta cultura" como la fase más elevada de la cultura occidental consagrada en los siglos XVIII y XIX (concierto, ópera, polifonía, danza, pintura, escultura y novela). La alta cultura en el porfiriato fue difundida y apoyada por el Estado mexicano con la creación de "recintos nacionales", mientras que la "cultura popular" se abrió espacios en los bailes de salón, los casinos y los jockeys club, teatros de revista, orfeones, bandas de guerra en los kioscos e inauguraciones de estaciones de ferrocarril.

${ }^{3}$ En mi tesis doctoral denomino a este suceso histórico como una especie de "diáspora" de profesores de música y alumnos del Conservatorio, contrarios al maestro Carlos Chávez por su intención de insertar la institución musical en las arterias de la Secretaría de Educación Pública. Finalmente, estos músicos disidentes se quedaron en la Universidad para fundar la Facultad de Música. ${ }^{4}$ En esta carta abierta de Carlos Chávez — difundida por el diario El Universal - en relación con el conflicto del Conservatorio de la Universidad, el maestro aclaró que era ciudadano mexicano por nacimiento, además de inexacto que haya solicitado al Gobierno Federal la separación del Conservatorio de la Universidad Nacional, puesto que sólo sustentó su criterio de que "México no necesitaba doctores ni bachilleres en música", sino buenos ejecutantes de orquesta, basado en buenos argumentos. Esto ante el reclamo de un grupo de alumnos del Conservatorio que exigieron su inmediata renuncia.

${ }^{5}$ El 10 de julio de 1929 se anunció la expedición de la Ley Orgánica de la Universidad Nacional Autónoma de México, y los estudiantes lograron reanudar sus labores tras un conflicto que había escalado en huelga desde el mes de mayo. Finalmente, esta ley dotó de autonomía a la Universidad, aunque de manera limitada. La autonomía se convirtió en un recurso para resistir la injerencia del Gobierno Federal en la orientación de la Universidad. En el rubro de las finanzas se suscitaron cambios radicales en perjuicio de la institución, asignándosele un subsidio del gobierno federal para desarrollar sus actividades hasta que la misma llegase a contar fondos enteramente suyos para lograr su independencia económica.
} 
septiembre ${ }^{6}$ había resuelto que la institución de música universitaria? llevara el nombre de "Facultad de Música" (Archivo Histórico de la Universidad Nacional Autónoma de México (AHUNAM), Fondo Universidad Nacional (FUN), sección Departamento de Administración (DA), c. 40, exp. 1211, f. 15150).

Una vez separadas ambas instituciones, y ante la petición de Carlos Chávez de que la UNAM siguiera suministrando al Conservatorio los gastos y materiales para su administración - argumentando un supuesto acuerdo verbal-, la respuesta de la Universidad fue contundente, ${ }^{8}$ como se puede leer en el siguiente documento:

le manifiesto que de conformidad con lo preceptuado en la Ley Orgánica de esta Universidad, y por haber pasado a depender ese Establecimiento a su cargo de la Secretaría de Educación Pública, ésta es la que debe proveerlo de todo lo necesario. Reitero a usted mi consideración muy atenta. POR MI RAZA HABLARÁ EL ESPÍRITU. México, D.F., a 28 de septiembre de 1929. EL TESORERO, JEFE DEL DEPARTAMENTO DE ADMON. (AHUNAM, FUN, sección DA, c. 7, exp. 114, f. 03271).

La respuesta a la petición de Chávez nos muestra claramente la postura que asumió la UNAM ante la separación del Conservatorio de sus entrañas; era inobjetable, la decisión de la ruptura no daría vuelta atrás; y es precisamente en este momento crucial donde me atrevo a plantear las siguientes interrogantes: ¿cuáles eran las propiedades específicas del campo artístico de los músicos - en cuanto a las agrupaciones musicales instrumentales- que les permitieron fortalecer su identidad dentro de la Universidad en la etapa donde el Conservatorio estuvo en su seno? ¿Cómo permeo el nacionalismo de los gobiernos posrevolucionarios y el proyecto cultural vasconcelista en el plan del Departamento de Extensión Universitaria? ¿Los músicos del conservatorio universitario continuaron siendo esos "destinatarios titulares" en su acercamiento con la alta cultura para ahora difundirla hacia las capas populares?

La interrogante que planteo sobre la influencia del nacionalismo y el proyecto cultural vasconcelista en el plan de trabajo del Departamento de Extensión Universitaria coincide, en cierta manera, con las conclusiones en el ámbito cultural de una de las investigaciones más rigurosas de Javier Garcíadiego (1996) sobre la historia de la Universidad. Este autor demostró que la Universidad Nacional transitó por tres facetas en el dominio cultural (1996: 408): a) la restauración parcial del espíritu Porfirio-sierrista, b) la gran renovación cultural del triunfo de la Revolución —nacionalismo-, y, c) los rasgos más sobresalientes del proyecto cultural vasconcelista. La enorme carga cultural y el impulso nacionalista fueron marcas indelebles en la cultura mexicana, afectando a las políticas educativas estatales como las vanguardias artísticas y musicales (Pérez, 2015: 19). En 1920, Adolfo de la Huerta designó a José Vasconcelos como jefe del Departamento Universitario y de Bellas Artes, en el cual este último puso en práctica sus ideas cultivadas en el interior del Ateneo de la Juventud, y diseñó estrategias que dieron fruto como la federalización de la educación pública, y la creación de una secretaría de Estado que rigiera los asuntos educativos y culturales del país (Tovar y de Teresa, 1994: 36-37); el vasconcelismo cimentó

\footnotetext{
${ }^{6}$ El 11 de septiembre, el maestro Estanislao Mejía había informado a José López Lira que, en la asamblea de alumnos universitarios de música efectuada en el edificio colonial de Mascarones, después de discutir el plan de estudios para la carrera de profesor y de concertista, se lograba un acuerdo para que el título del "Conservatorio" fuera cambiado por el de "Facultad de Música". Sólo faltaba la ratificación presentada en este documento.

${ }^{7}$ Refiriéndose al Centro Universitario de Estudios Musicales (en sustitución de lo que fuera el Conservatorio).

${ }^{8}$ Esta contestación se plasmó en un oficio sobre la tramitación de acuerdo dirigido al director del Conservatorio de Música.
} 
las bases de un nacionalismo cultural apoyado en valores y símbolos estéticos y culturales como el "muralismo"; de tal manera que nos remitimos a una etapa crucial en donde, parafraseando a Pérez Vejo (1999: 17): "Las naciones se inventan, pero no a partir de decretos y normas políticas, sino de valores simbólicos y culturales". Vasconcelos convenció a los poderes locales de crear una secretaría de educación con jurisdicción nacional, devolver a la Universidad sus funciones - reintegrarle la Escuela Nacional Preparatoria-, y comprometerla con una obra de educación popular y de regeneración moral (Loyo, 2010: 160). En los gobiernos posrevolucionarios la educación se convirtió en el vehículo homogeneizador de la política cultural, ${ }^{9}$ sellándose una especie de binomio "educación-cultura" a partir de la fundación de la Secretaría de Educación Pública (SEP), para finalmente romperse con la orientación de políticas públicas de los gobiernos neoliberales, y la creación de la Secretaría de Cultura en el 2015 (Beristáin, 2018: 202).

El periodo de estudio de esta investigación (1917-1929) inicia con la inclusión - en el carrancismo - del Conservatorio Nacional dentro de la Universidad, y finaliza en el año donde se separan ambas instituciones. Esta etapa atraviesa los años veinte ${ }^{10}$ década en donde se articulan y disputan definiciones de cultura en el sentido de la identidad y la ciudadanía nacional (Vaughan, 2001: 15), y en que el reconocimiento de lo popular - el pueblo - sirvió de legitimación discursiva para los programas de gobierno (Pérez, 1999: 182). En el caso específico de la UNM, ésta logró empatarse con los propósitos de los gobiernos posrevolucionarios, y así sucedió durante el periodo del presidente Plutarco Elías Calles (19241928) y sus compromisos con la liberación económica y el desarrollo educacional. La Universidad Nacional a través de acciones culturales emprendidas por su Departamento de Extensión Universitaria, desde 1925, ratificó su compromiso - el cual se plasmó en su informe de actividades de 1929- de hacer ciencia con un significado de alto interés social, como germen de una intelectualidad más generosa, en una especie de unión o encuentro de las "clases intelectuales con las clases laborantes"11 (AHUNAM, FUN, sección DA, c. 30, exp. 851, ff. 12287-12289).

El objetivo principal de este artículo es lograr identificar las propiedades específicas establecidas en el campo artístico para fortalecer la identidad de los músicos del conservatorio universitario en la proyección de agrupaciones musicales instrumentales - orquestas de alumnos y de música de cámara-; todo esto a través de un adecuado análisis sociológico e histórico aterrizado en el ámbito artístico y pedagógico del periodo, en un tema escasamente explorado, así como de una rigurosa revisión y articulación de documentos inéditos del Fondo Universidad Nacional, sección Departamento de Administración, del Archivo Histórico de la Universidad Nacional Autónoma de México (AHUNAM).

\footnotetext{
${ }^{9}$ Se puede concebir a la política cultural como la orientación de las acciones del Estado en la rectoría de la cultura. En los gobiernos posrevolucionarios se articularon de mejor manera las políticas culturales, se generaron procesos y condiciones para generar lugares orgánicos que orientaran el patrimonio cultural para las siguientes generaciones, creándose así el Instituto Nacional de Antropología e Historia (INAH) y el Instituto Nacional de Bellas Artes y Literatura (INBAL), este último absorbió las funciones del Departamento de Bellas Artes, coordinó las funciones pedagógicas del Conservatorio Nacional de Música y su propia orquesta sinfónica, incluso el recinto del Palacio de Bellas Artes quedó bajo su gestión (Beristáin, 2018: 209).

${ }^{10}$ Este periodo de estudio se puede encuadrar dentro del proyecto de la "Revolución de (1910-1940)" y sus logros, para una unidad de análisis válida, como refiere Alan Night (2015: 24).

${ }^{11}$ A principios de 1929, el Departamento de Extensión Universitaria presentó su Informe sobre la obra cultural que realizó en los años 1926, 1927 y 1928. El informe incluyó temas de conferencias, colaboradores, instituciones, número de profesores que prestaron servicios en los centros de Extensión Universitaria, número de alumnos que concurrieron a las clases impartidas en éstos, número de clases dictadas, incluyendo los importes erogados. En marzo del mismo año, la Universidad Nacional difundió y distribuyó entre sus profesores y empleados la memoria de los trabajos realizados por la Universidad Nacional durante la administración del presidente General Plutarco Elías Calles.
} 
En las fuentes encontradas y utilizadas para este artículo se destacan documentos relacionados con la pertenencia universitaria, tales como subvenciones económicas, nombramientos, reglamentos y programas de conciertos; documentos de posiciones de poder o de autoridad como distinciones, reconocimientos y homenajes; documentos de términos de referencia oficiales como los referentes a miembros de jurado o consejos; y documentos que nos plasman la forma de titulación, como los planes de estudio.

\section{El campo artístico de los músicos}

El enfoque de análisis de este artículo está basado en el supuesto de los músicos mexicanos como "destinatarios titulares" en su acercamiento a la alta cultura, para llevarla a las capas populares ${ }^{12}$ en el contexto del nacionalismo, los cuales forman parte de un "campo" artístico con propiedades específicas. Los conceptos de "campo artístico" y "destinatarios titulares" están sustentados en la producción de las obras del filósofo y sociólogo francés Pierre Bourdieu (1930-2002). Bourdieu (2011: 28) nos habla de un "espacio social", basado en la noción misma de "espacio", es decir, de un "conjunto de posiciones distintas y coexistentes, exteriores las unas respecto de las otras, definidas las unas en relación con las otras, por vínculos de proximidad, de vecindad, o de alejamiento"; dentro de este espacio, en las sociedades modernas la vida social se reproduce en "campos" (económico, político, científico, artístico) que funcionan bajo una fuerte interdependencia. Los elementos esenciales que constituyen un campo son la existencia de un "capital" común (conocimiento, habilidades, creencias, etcétera) y la "lucha" por su apropiación, es decir, aquella disputa entre quienes detentan el capital y la de quienes aspiran a poseerlo (Bourdieu, 1990: 19).
Bourdieu afirma que la "historia del campo es la historia de la lucha por el monopolio de la imposición de las categorías de percepción y de valoración legítimas", que dentro del mismo se da un combate entre aquellos (me atrevo a posicionar aquí el caso de los músicos del conservatorio universitario) "que hicieron época y que luchan por seguir durando, y aquellos que a su vez no pueden hacer época sin remitir al pasado a aquellos a quienes interesa detener el tiempo, eternizar el estado presente; entre los dominantes conformes con la continuidad, la identidad, la reproducción, y los dominados, los nuevos que están entrando y que tienen todas las de ganar con la discontinuidad, la ruptura, la diferencia, la revolución" (1995a: 237). Todo campo crea su "habitus", es decir, su forma particular de presentarse en la sociedad, desde el lenguaje propio hasta la manera de vestir. El habitus es un mecanismo estructurante que opera desde dentro los sujetos, es el principio generador de las estrategias y reacciona a las solicitaciones del campo en forma coherente y sistemática; tanto el habitus como el campo son relacionales, en otras palabras, funcionan el uno en relación con el otro (1995b: 25).

Las academias, en nuestro caso el conservatorio universitario, forman parte de un sistema de interacciones de un campo intelectual, el cual mantiene relaciones de interdependencia con las estructuras del campo cultural; éstas consagran, por su actividad y su enseñanza, un género de obras y un tipo de hombre cultivado: "Todo acto cultural, creación o consumo, encierra la afirmación implícita del derecho de expresarse legítimamente" (2002b: 33). El campo cultural es el sistema de relaciones que incluye a los artistas, editores, críticos y el público, que determina las condiciones específicas de producción y circulación de sus productos. Las academias como

\footnotetext{
${ }^{12}$ En la cultura popular en el porfiriato la opinión pública burguesa y la sociedad civil se posesionaron de jardines y parques a través de los orfeones. En la década de los veinte del siglo XX, los músicos mexicanos trabajaron paralelamente en ambas nociones, en salas de concierto difundiendo la alta cultura, y en vecindades interpretando jazz, fenómeno de la cultura popular. A estas actividades paralelas, los propios músicos las denominaron "el hueso". En los gobiernos posrevolucionarios las salas de concierto abrieron sus puertas para ofrecer conciertos a trabajadores obreros y para el público infantil.
} 
instituciones escolares ocupan un lugar homólogo al de la Iglesia, al delimitar "entre lo que merece ser transmitido y adquirido y lo que no lo merece, reproduce continuamente la distinción entre las obras consagradas y las obras ilegítimas" (1995a: 222-223). Bourdieu sugiere que cada que se estudie un campo determinado, se debe intentar descubrir sus propiedades específicas. Las propiedades establecidas que propone Bourdieu para construir la identidad de los universitarios incluyen los "títulos puestos al frente en la auto presentación", la "pertenencia universitaria", las "posiciones de poder o de autoridad" y los "títulos universitarios" (2009: 20).

Trasladando los conceptos de Bourdieu al caso de los músicos del conservatorio universitario, me atrevo a interpretar que éstos, como destinatarios titulares dentro del campo artístico, recrearon, reinterpretaron y transformaron el legado de sus generaciones anteriores. Los músicos del conservatorio fortalecieron su identidad como universitarios a través de un conjunto de propiedades establecidas como: los títulos puestos al frente en la autopresentación (membretes oficiales y documentos de identidad), de pertenencia universitaria (subvenciones económicas, nombramientos, conciertos, reglamentos), posiciones de poder o de autoridad (distinciones, reconocimientos, homenajes), términos de referencia oficiales (miembros de jurados o consejos), hasta la forma de titulación (planes de estudio). Es muy importante para Bourdieu el efecto de la "titulación académica", puesto que vincula a la familia, escuela y cultura. El autor encuentra una fuerte correlación entre la competencia en materia de música y el capital escolar (saber acumulado), este último producto de la transmisión cultural asegurada por la familia y de la transmisión cultural asegurada por la escuela (2002a: 20).

\section{La orquesta del Conservatorio Nacional de Música}

Don Agustín Caballero ${ }^{13}$ inauguró y dirigió el Conservatorio de la Sociedad Filarmónica Mexicana, en 1866, el cual se constituyó como resultado del reconocimiento de las élites a los músicos mexicanos por el hecho de rodearlos y recrearlos de sus habilidades artísticas (Beristáin, 2016: 53), y de esta manera lograr ser más productivos y contribuir con su bienestar al profesionalizar su actividad; así lo argumentaron y redactaron en su reglamento orgánico. En la Memoria de la Sociedad Filarmónica Mexicana (1868), se mencionan algunos nombres de sus fundadores "Los Sres. Durán, Ortega, Fonseca, León, Clement, Siliceo D. Manuel y otros que omitimos por no difundirnos demasiado". Durante la segunda mitad del siglo XIX, se dio en México una especie de "fiebre asociacionista", brotando por todos lados congresos científicos, asociaciones de obreros y sociedades artísticas (Rodríguez, 2012: 430). La sociedad Filarmónica Mexicana argumentó en su Memoria de 1868, el papel de las élites con la sociedad decimonónica "La Sociedad Filarmónica ha podido sostenerse, porque no ha hecho sino interpretar una gran necesidad de nuestro pueblo, porque ha contestado a las exigencias de una sociedad ilustrada y progresista".

El Conservatorio se convirtió en el pilar donde la Sociedad Filarmónica Mexicana enfocaría sus energías, según está registrado en su memoria:

\footnotetext{
Constituida la Sociedad, no con un espíritu puramente de recreo o entretenimiento, sino con deseos positivos de practicar el bien, de mejorar las clases sociales, y de una utilidad práctica y civilizadora, continuó prestando su atención más decidida a la
}

\footnotetext{
${ }^{13}$ El presbítero D. Agustín Caballero dirigió la primera compañía de Ópera Nacional en México, tras la invasión norteamericana. En 1839, fundó el instituto musical Academia Beristáin-Caballero — antecedente del Conservatorio-, el cual al morir Joaquín Beristáin siguió dirigiendo (El Nacional, 27/III/1949).
} 
organización del Conservatorio, que era el desiderátum de su instalación. Para lograr el objeto que se propuso, no desmayó en sus gestiones cerca del supremo gobierno, habiendo sido coronadas del éxito más feliz, pues este cedió el edificio que actualmente ocupa (Memoria de la Sociedad Filarmónica Mexicana, 1868).

En enero de 1868, abrió sus puertas en su nuevo local el Conservatorio de Música, todavía no nacional, pero ajustándose a la Ley de Instrucción Pública expedida el 2 de diciembre del 1867. El presidente don Sebastián Lerdo de Tejada, en su informe al H. Congreso de la Unión leído el 16 de septiembre de 1875, mencionó claramente al Conservatorio de Música como institución subvencionada, pero todavía no nacional. Para el día 13 de enero de 1877, el Gobierno de la República expidió su decreto firmado por D. Ignacio Ramírez, nacionalizando el Conservatorio de Música (El Ilustrado, 18/XI/1937).

Esta especie de institucionalización de la Sociedad Filarmónica en un Conservatorio de Música, basada en la insistencia del reconocimiento del Estado mexicano, podemos considerarla dentro de un conjunto de esfuerzos donde se entendió a la música como un poderoso agente de identidad "constructora", tarea que de acuerdo con los investigadores Ricardo Miranda y Aurelio Tello (2011: 53-54), se dio en dos grandes sentidos; primero, en la construcción de instituciones, ${ }^{14}$ generando las condiciones propicias para el cultivo y florecimiento musical, y segundo, el carácter pedagógico, la difusión de libros de teoría y enseñanza de la música.
En 1882, se fundó la Orquesta del Conservatorio Nacional, bajo la dirección en el Conservatorio de Alfredo Bablot, ${ }^{15}$ la cual se conformó de maestros y alumnos de la institución, así como de integrantes de la Orquesta de Santa Cecilia y de la Ópera (Zanolli, 1997: 177-179). Para Bablot, la orquesta contribuiría al lucimiento de las fiestas nacionales e imprimiría un poderoso impulso al movimiento musical del país (Moreno, 2009: 43).

\section{Imagen 1. Alfredo Bablot}

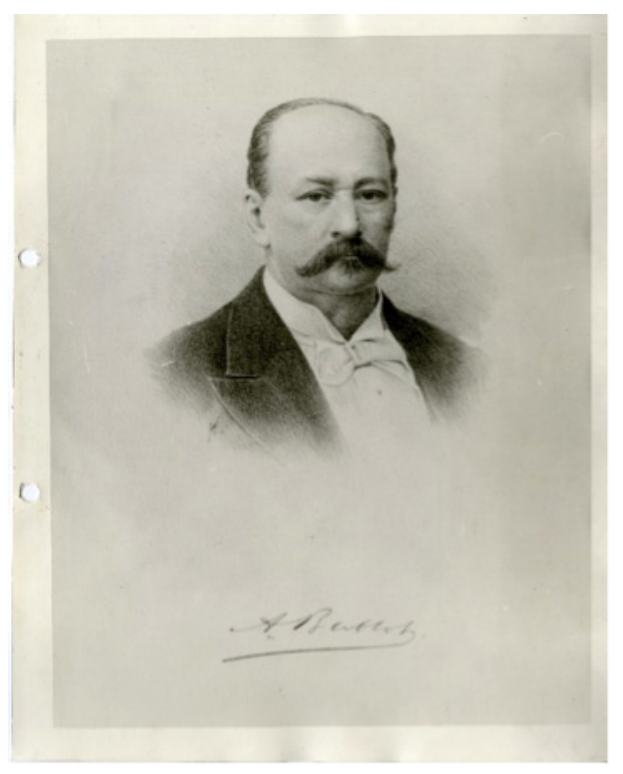

Fuente: Biblioteca Nacional, del Archivo de Iconoteca, Archivo de Expedientes.

En 1902, la Orquesta del Conservatorio Nacional recayó en la batuta del músico mexicano Carlos J. Meneses, recibiendo por primera vez una institución

\footnotetext{
${ }^{14}$ Una de las investigaciones en la cual se puede apreciar de mejor manera el proceso de creación de instituciones científicas y literarias en México, en su trayecto historiográfico, es la obra coordinada por la Dra. Rosalina Ríos Zuñiga: "Instituciones modernas de educación superior. Institutos científicos y literarios de México, siglos XIX y XX” (2015). Los políticos decimonónicos crearon instituciones educativas que estuvieran acordes a los nuevos tiempos y su contexto histórico, sobreviviendo incluso a años de gran turbulencia política, económica y de profundas transformaciones socioculturales. Como bien señala Ríos Zuñiga, estas instituciones contaron con similitudes en su estructura, organización y planes de estudio, formando en los distintos estados de la República mexicana a muchos profesionistas que posteriormente irían ocupando cargos en la burocracia civil.

${ }^{15}$ Alfredo Bablot se estableció en México en 1849 como secretario particular de la cantante Ana Bishop. Periodista, escritor y crítico musical, participó en la fundación de la Sociedad Filarmónica Mexicana. Al fundarse la orquesta del Conservatorio de Música, acordó que todos los profesores del plantel, sin excepción, asumieran por turnos la dirección de la orquesta, y de esa manera juzgar cuál profesor sería el más apto para darle continuidad a su batuta.
} 
musical en nuestro país una "subvención económica" por parte del Estado mexicano; subvención resultado más de las redes de relaciones de amistad entre los músicos mexicanos y la élite porfirista, que de una política cultural articulada. El ministro Limantour, en ese entonces secretario de Hacienda y Crédito Público, llegó a interceder ante don Joaquín Baranda, secretario de Justicia e Instrucción Pública, para que el maestro Meneses pudiera viajar a Europa, con goce de sueldo, y perfeccionar sus estudios. La subvención económica no solamente fue fundamental para incentivar a los músicos integrantes de la orquesta, sino también se convirtió en un fuerte vínculo de identidad de los músicos del Conservatorio con el Estado mexicano.

\section{El Conservatorio en el seno de la Universidad}

En 1915, por acuerdo del Primer Jefe del Ejército Constitucionalista se creó la Dirección General de las Bellas Artes (como parte de una reorganización al interior de la Secretaría de Instrucción Pública), en cuyas dependencias se incluyó al Conservatorio Nacional de Música y Arte Dramático (Boletín de la Secretaría de Instrucción Pública, 1915). Un año después, por acuerdo de la propia Dirección General de las Bellas Artes, la antigua Orquesta del Conservatorio Nacional de Música cambió al nombre de Orquesta Sinfónica Nacional, mientras que el Conservatorio Nacional de Música se convirtió en la Escuela Nacional de Música y Arte Teatral (Boletín de la Secretaría de Instrucción Pública, 1916). ${ }^{16}$ La Dirección General de las Bellas Artes organizó su primera conferencia sobre "carreras artísticas" - en el Anfiteatro de la Escuela Nacional Preparatoria- en enero de 1917, dedicada a jóvenes que optaban por elegir una profesión "La entrada es libre y el programa es el siguiente: I. Sonata de Corelli, por el profesor don José Rocabruna. II. La Música. Conferencia por la señorita Alba Herrera y Ogazón. ${ }^{17}$ III. Aria de Bach para violín, con acompañamiento de órgano. Profesor don José Rocabruna y señorita Julia Alonso" ( $E l$ Nacional, 5/I/1917).

El presidente Venustiano Carranza expidió el 25 de diciembre de 1917, la Ley de Secretarías de Estado, en la cual se crearon siete secretarías de Estado (Gobernación, Relaciones Exteriores, Hacienda y Crédito Público, Guerra y Marina, Agricultura y Fomento, Comunicaciones y Obras Públicas e Industria, Comercio y Trabajo) y cinco departamentos (Universitario y de Bellas Artes, Salubridad Pública, Aprovechamientos Generales, Establecimientos Fabriles y Aprovisionamientos Militares, y Contraloría) (Acosta, 1973: 295). De esta manera desaparece la Secretaría de Instrucción Pública y Bellas Artes, y la Universidad Nacional y sus escuelas de Jurisprudencia, Ingeniería y Medicina se integran al Departamento Universitario y de Bellas Artes, el cual llegaría a contar con un director y al mismo tiempo rector. La vulnerabilidad de la Universidad fue latente al convertirse en una dependencia político-burocrática (Garcíadiego, 1996: 345-348). En agosto de 1920, el presidente Adolfo de la Huerta designó a José Vasconcelos como jefe del Departamento Universitario y de Bellas Artes, quien se encargaría de realizar el proyecto de la creación de la

\footnotetext{
${ }^{16}$ Diversos documentos revisados en el AHUNAM, de los años 1927 y 1928, nombran a la institución musical como Conservatorio Nacional de Música, y otros en 1929, como Escuela Nacional de Música, Teatro y Danza. Ambos nombres se refieren a la misma institución. El que predomine el nombre de Conservatorio de Música, puede deberse a la fuerte presencia y trayectoria de éste en el ámbito musical.

${ }^{17}$ La profesora Alba Herrera y Ogazón (1885-1931) fungió como historiadora de la música, crítica musical, profesora del Conservatorio, fundadora de la facultad de música de la UNAM, pianista y solista de la Orquesta Sinfónica Nacional dirigida por Julián Carrillo, así como precursora de la musicología en nuestro país. Sus inicios musicales se dieron bajo las lecciones privadas con Carlos J. Meneses, Pedro Luis Ogazón y Ricardo Castro. En su libro "El arte musical en México" (1917) incluyó un apartado —-muy interesante - sobre el Conservatorio, develando los altibajos de éste, y describiendo a sus fundadores como músicos de su tiempo con la urgencia moral y material de trabajar para otros.
} 
Secretaría de Educación Pública (SEP) consiguiendo su aprobación y puesta en marcha. La Universidad Nacional se integra a este recién ministerio recuperando varias de sus funciones. El Conservatorio de Música continuó en el seno de la Universidad Nacional hasta 1929, el año del conflicto de la autonomía universitaria.

\section{La pertenencia de los músicos del conservatorio universitario}

Poco se ha escrito sobre los músicos del Conservatorio en su etapa dentro de la Universidad $\mathrm{Na}$ cional (1917-1929), sin embargo, escudriñando las fuentes en el Archivo Histórico de la institución universitaria, descubrí una serie de elementos que me permitieron develar la manera en que se fortaleció la identidad de estos músicos universitarios a través de un conjunto de propiedades establecidas en su campo artístico. Una de estas propiedades es la "pertenencia", en la cual podemos incluir: a) los nombramientos - que van desde los profesores de asignatura hasta directores de orquestas de alumnos--, b) la difusión, a través de conciertos de la Orquesta de Alumnos del Conservatorio - posteriormente de la Facultad de Música-, y de la Agrupación Universitaria de Música de Cámara (en este rubro es fundamental el impulso del Departamento de Extensión Universitaria); c) los reglamentos o lineamientos para la adecuada operación de las agrupaciones musicales instrumentales, y d) las subvenciones económicas, que consistieron en apoyos que recibieron los alumnos integrantes de la orquesta representativa y la agrupación de música de cámara, para sus gastos de traslados a ensayos y conciertos, así como para mantenimiento de sus instrumentos.

\section{Imagen 2. Silvestre Revueltas}

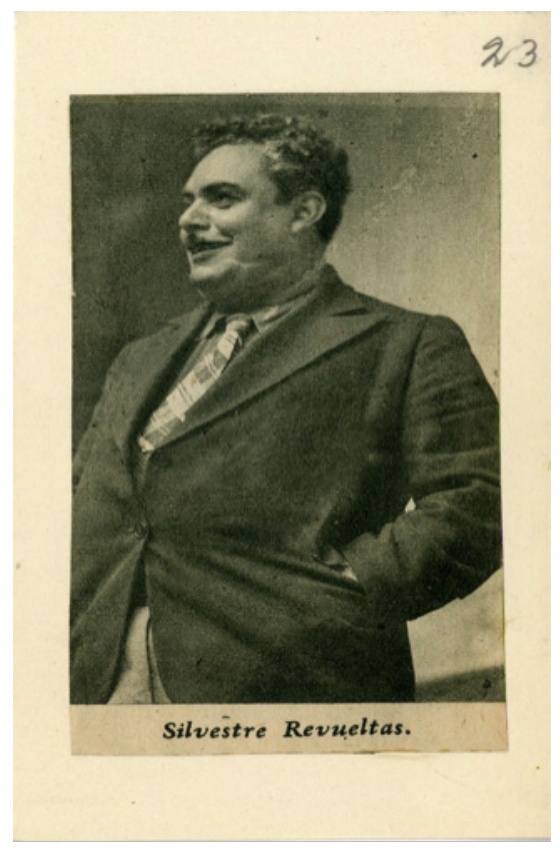

Fuente: Biblioteca Nacional, del Archivo de Iconoteca, Archivo de Expedientes.

Como una muestra de la subvención económica como elemento de pertenencia en el campo de los músicos, presento una relación de la pagaduría de la Universidad Nacional en donde se asignaron $\$ 500.00$ mensuales, en 1929, para la subvención de la Orquesta de Alumnos del Conservatorio de Música. En marzo de este mismo año, la orquesta dirigida por el maestro Silvestre Revueltas, estaba conformada por los siguientes músicos que aparecen en la lista, y de esta manera se les distribuyó la subvención:

Violín primero. Micheline Reichert (\$10.00), Higinio Ruvalcaba (\$10.00), Bonifacio Zárate (\$10.00), Pascual Hernández (\$10.00), Luis Guzmán (\$9.05), Inocencio Cervantes (\$9.05), J. Jesús Mendoza (\$9.81), Armando Echeverría (\$10.00), Jesús Santana (\$4.75), Catalina Cedillo (\$1.33), Fernando Jordán (\$8.67), Agustín García Z. (\$10.00), Estanislao Morales (\$9.43), Jesús R. González (\$4.56). 
Violín segundo. Raquel Calero (\$10.00), Rebeca Andrade (\$9.05), Raquel Andrade (\$9.05), Patra María Baca (\$9.05), Luis Sandi Meneses (\$8.86), Daniel Ayala (\$7.15), Luis Villalobos (\$10.00), José Cisneros (\$9.05), Vicente Montes (\$8.86), Rafael Valdez Fraga (\$9.43), Leonidas Rodríguez (\$9.05), José González (\$8.67), Benito Juárez (\$10.00).

Viola. David Elizarraraz (\$10.00), Pedro Andrade (\$3.80), Angel Rocha Jr. (\$2.85), Daniel Saloma (\$8.86). Violoncello. Luis Galindo (\$10.00), José López Flores (\$8.10), Jesús Reyes (\$8.67), Miguel Lara (\$8.86), Ricardo Ramírez (\$8.86), Isaías L. Santos (\$4.56).

Contrabajo. Isaías Mejía (\$7.72), Tomás Ponce Reyes (\$8.10), León Ramírez $(\$ 7.15)$, Aurelio Osorio $(\$ 3.80)$.

Arpa. Josefina González (\$4.11).

Flauta. Francisco Vázquez (\$6.20), Hernán Loria (\$7.15).

Oboe. Miguel Miranda (\$2.66), Miguel Ruíz $(\$ 8.10)$.

Glarinete. Aurelio Ocampo (\$8.86), Severo González (\$3.80), Margarito Padilla (\$10.00).

Fagot. Gregorio Vargas (\$10.00).

Corno. Candelario Huizar (\$10.00), Liborio Blanco (\$9.81).

Trombón. David Vázquez (\$5.13), Juan Mendoza (\$9.62), Fernando Rivas (\$8.17), Serafín Mendoza (\$9.67), Felipe Escorcia (\$4.75).

Timbales. José Arévalo (\$7.60), Felipe Luyando $(\$ 10.00)$.

Batería. Ricardo P. Bravo (\$6.27).

Órgano. S. Pichardo (\$2.85) (AHUNAM, FUN, sección DA, c. 29, exp. 799, ff. 11861-11864).

\section{El Departamento de Extensión Universitaria y la difusión artística}

En 1929, el Departamento de Extensión Universitaria presentó un Informe sobre sus actividades desarrolladas durante los años 1926, 1927 y 1928. En dicho informe se descubren aspectos por más interesantes. El Plan General de Trabajo del departamento dividió sus actividades en: conferencias, centros de extensión universitaria, ${ }^{18}$ difusión artística, difusión cultural por radio, infantil y cooperación social. La obra cultural de la Universidad se inspiró en tres principios fundamentales: "realizar una intensa propaganda de cultura de acuerdo con el medio en donde ésta se desarrolla; provocar la iniciativa privada para que coopere en la obra de difusión de cultura; y fomentar activamente la obra de servicio social" (AHUNAM, FUN, sección DA, c. 30, exp. 851, f.12290).

La actividad musical fue preponderante en la sección de Difusión Artística "Los trabajos de esta sección se han realizado en las sociedades obreras, en las fábricas y talleres, en las carpas, en prisiones y establecimientos de corrección, en parques y jardines y en lugares de excursión. Las labores han comprendido. a) Conciertos y recitales de piano. b) Recitales poéticos. c) Conciertos por radio. d) Veladas" (AHUNAM, FUN, sección DA, c. 30, exp. 851, f.12305). En una nota final del informe, se destacó la contribución del Conservatorio Nacional de Música, bajo la dirección del profesor Carlos del Castillo, ${ }^{19}$ "Se propuso coadyuvar a la extensión universitaria con cuatro series de conciertos, a saber: seis conciertos dedicados a los niños; seis conciertos populares,

\footnotetext{
${ }^{18}$ Los centros de Extensión Universitaria que se incluyen en el informe de actividades son: General Anaya, D.F., Escuela "Gertrudis Armendáriz de Hidalgo" No. XVI, Alianza de Ferrocarrileros Mexicanos, Alianza de Obreros y empleados de la Compañía de Tranvías de México, S.A., Centro de Extensión Universitaria de Tacuba, Sociedad Mutualista "Obreros Libres", "Centro Fray Bartolomé de las Casas" del Municipio de Ixtapalapa, D.F., y la Escuela "Ignacio L. Vallarta". El número de alumnos que asistieron a clases a estos centros fueron: 207 (1926), 567 (1927) y 470 (1928). La Universidad, entre 1925 y 1928, destinó a los centros de extensión la cantidad de $\$ 12,636.00$ para el pago de servicios prestados por profesores.

${ }^{19}$ El maestro Carlos del Castillo asumió la dirección del Conservatorio en el periodo 1923-1928, y de propias palabras del maestro Estanislao Mejía, en los Anales de la Escuela Nacional de Música e Historia de la Educación Musical en México (1947), bajo su gestión se le inyectó un poco de vigor al Conservatorio, a través del fomento de audiciones públicas con obras pertenecientes al género polifónicovocal (Bach, Haydn, Mendelssohn y Saint-Saens).
} 
dedicados especialmente a los obreros; seis conciertos históricos, desde los griegos hasta nuestros días; y seis conciertos para estimular y dar a conocer las producciones musicales de los compositores mexicanos" (AHUNAM, FUN, sección DA, c. 30, exp. 851, f. 12305). Los programas del Departamento de Extensión Universitaria se organizaron, y de esta manera lo enfatizaron en el "Informe de actividades", de acuerdo con las necesidades que tenían las "clases menos favorecidas del pueblo".

El estímulo y difusión de las producciones musicales de los compositores mexicanos que se mencionan en las actividades del Conservatorio son resultado de los congresos nacionales de Música que se efectuaron en 1926 y 1928. Estos congresos se convirtieron en un espacio vital de ideas y debates acalorados entre los músicos mexicanos para fijar distintas posturas, desde replantear el papel del Conservatorio en la sociedad, resolver el problema de escasez de alumnos, impulsar los cursos de Historia de la Música en México, reajustar las 12 notas de la escala cromática, hasta promover el trabajo de campo meramente antropológico de la música indígena. Finalmente, los congresos de música sirvieron para estrechar la identidad nacional con la música. ${ }^{20}$

\section{La Agrupación Universitaria de Música de Cámara}

Dentro de las propiedades de "pertenencia" en el fortalecimiento de la identidad de los músicos del Conservatorio en la Universidad, el caso del Acuerdo \#3 — signado el 26 de enero de 1926-, nos refleja las luchas internas al interior del campo artístico de los músicos, entre aquellos profesores de música que han dejado un legado, los nuevos profesores que ingresan al campo, y la institución que desarrolla mecanismos para fortalecer su vínculo con los propios músicos. Alfonso Pruneda, rector de la Universidad, comunicó el Acuerdo \#3 al secretario general de ésta, el cual consistió en que en todo acto que participara la Agrupación de Música de Cámara del maestro Carlos J. Meneses tomara el nombre de "Agrupación Universitaria de Música de Cámara", ${ }^{21}$ puesto que ésta era remunerada por sus servicios prestados a la Universidad (AHUNAM, FUN, sección DA, c. 7, exp. 113, f. 03259).

En julio de 1927, el Departamento de Extensión Universitaria, presentó un programa de audición titulado "Liszt, Cesar Franck", en el cual se anunció la participación de la Agrupación de Música de Cámara del maestro Meneses, sin respetar el acuerdo \#3 (AHUNAM, FUN, sección DA, c. 7, exp. 113, ff. 03262-03263). En el repertorio del programa se destacaban piezas como el "Quinteto para piano" de César Franck y el "Gran concierto en mi b" de Franz Liszt. Franck, de los representantes del posromanticismo, heredero del romanticismo y del despertar de las culturas nacionalistas, y Liszt, precursor del nacionalismo musical con sus Rapsodias húngaras (Álvarez, 2014: 104-107). El 8 de agosto del mismo año, el jefe del Departamento de Administración de la Universidad Nacional dirigió un recordatorio al maestro Meneses sobre el Acuerdo \#3:

\footnotetext{
A fin de cumplimentar el acuerdo del C. Rector, en que se dispuso se designara a la institución artística que dignamente dirige usted, con el nombre de
}

\footnotetext{
${ }^{20}$ Para conocer en mejor detalle las ponencias y debates de los congresos nacionales de Música de 1926 y 1928, es indispensable revisar los trabajos de la Dra. María Esther Aguirre Lora, investigadora del Instituto de Estudios sobre la Universidad y la Educación (IISUE), tales como "Memoria en el tiempo. La Escuela Nacional de Música de la UNAM (ca. 1929-1945)" (2006) y "Preludio y fuga. Historias trashumantes de la Escuela Nacional de Música de la UNAM" (2008). Coincido con la Dra. Aguirre en que estos congresos también sirvieron para renovar el espíritu musical de la década de los veinte.

${ }^{21}$ El rector de la Universidad pide comunicar el Acuerdo \#3 al maestro Meneses, al director del Conservatorio y al encargado de organizar la Extensión Universitaria.
} 
Agrupación Universitaria de Música de Cámara, le hago atenta súplica de que me preste su valiosa cooperación en ese sentido, recomendando que en las invitaciones y programas de actos en que tome parte, se le haga figurar con la denominación indicada (AHUNAM, FUN, sección DA, c. 7, exp. 113, f. 03264).

En enero de 1928, el Departamento de Administración de la Universidad Nacional giró una orden de pago por la cantidad de $\$ 2400.00$ para cubrir la subvención anual de la Agrupación Universitaria de Música de Cámara a razón de \$200.00 mensuales (AHUNAM, FUN, sección DA, c. 29, exp. 799, f. 11867). En septiembre de 1929, la nómina del personal de la Agrupación Universitaria de Música de Cámara, bajo la batuta de Luis G. Saloma - profesor de Conjuntos de Cámara-, aún siendo Carlos Chávez director del Conservatorio, incluyó a los siguientes músicos:

Bonifacio Zárate (\$12.12), ${ }^{22}$ Consuelo Guevas Ney (\$18.18), Lucrecia Méndez (\$6.06), Rebeca Andrade (\$6.06), Raquel Andrade (\$6.06), Olga Flores Rivas (\$6.06), Jesús Reyes (\$18.18), Jesús Mendoza (\$18.18), Libertad Montelongo (\$18.18), Manuel Núñez (\$12.12), Paz Villalobos (\$18.18), Luis Guzmán (\$6.06), Daniel Saloma (\$6.06), Fernando Jordán (\$12.12), Francisco Cruz (\$12.12), Esmeralda González (\$18.18), y Esperanza Alarcón (\$6.08) (AHUNAM, FUN, sección DA, c. 29, exp. 799, f. 11866).

\section{Reconocimientos a músicos directores de orquesta en la Universidad}

El "reconocimiento" es otro de los elementos vitales de las propiedades de pertenencia en la conformación de la identidad de los músicos del Conservatorio universitario, y uno de los más representativos que otorgó la Universidad en nuestra etapa de estudio, lo realizó a manera de homenaje al distinguido profesor Carlos J. Meneses, quien además de dirigir la Agrupación Universitaria de Música de Cámara, fue director de la Orquesta Sinfónica del Conservatorio en el porfiriato, consiguiendo por primera vez el subsidio económico del Estado mexicano. Los profesores de música, como directores de orquesta, gozaron con un grado elevado de prestigio en el campo artístico de los músicos, "La dirección de orquesta está en la cúspide de una verdadera pirámide de información y requiere del dominio de una técnica particular, así como de conocimientos muy profundos en muchas ramas de la música, el arte, la historia, las ciencias y las humanidades, tanto en áreas generales como en terrenos especializados" (Velazco, 1988: 468).

El 20 de abril de 1928, Alfonso Pruneda, rector de la Universidad Nacional, dirigió un oficio al Presidente Municipal del H. Ayuntamiento de México solicitando permiso para disponer del Teatro Arbeu sin necesidad de erogar ningún impuesto. El motivo de la solicitud era la realización de un festival:

\footnotetext{
"Para rendir justo homenaje al distinguido maestro don Carlos J. Meneses, que por muchos años ha prestado sus servicios en el Conservatorio N. de Música, un grupo de personas de su amistad y varios de sus alumnos antiguos, resolvieron organizar bajo los auspicios de esta institución, un festival para tributarle ese honor bien merecido por su laboriosidad constante en las enseñanzas a que ha dedicado su vida" (AHUNAM, FUN, sección DA, c. 18, exp. 464, f. 07920).
}

La Tesorería Municipal exentó de todo impuesto a la Universidad Nacional, para la realización del

\footnotetext{
${ }^{22}$ Entre paréntesis se muestra la cantidad mensual en pesos percibida por cada músico.
} 
festival homenaje programado para el domingo 29 de abril.

El festival homenaje al maestro Carlos J. Mene$\operatorname{ses}^{23}$ se efectuó con éxito, y la invitación-programa misma destacó el motivo principal "por su talento y su gran significación en el progreso del Arte musical en México":

\section{PROGRAMA.}

I. ler. tiempo del Concierto en la menor... Grieg. Piano y orquesta. María García Genda, discípula del maestro Meneses. Director: Maestro José Rocabruna.

II. Apología del maestro Meneses... Sr. Carlos González Peña.

III. El Danubio azul. Arabescos... StraussSchulz-Evler. Piano. Magdalena Díaz, discípula del maestro Meneses.

\section{INTERMEDIO.}

IV. Sinfonía patética en si menor... Tschaikowsky. I. Adagio-Allegro-Andante-Allegro vivoAndante. II. Alegro Molto Vivace. Tarantella e Marcia. III. Adagio lamentoso. Orquesta. Director: Maestro Carlos J. Meneses.

V. Ofrecimiento de una corona al maestro, por sus discípulos, amigos y admiradores.

Piano "STEINWAY". Únicos agentes: A. WAGNER Y LEVIEN, ${ }^{24}$ SUC.S., S. en C. 1a. Capuchinas 21 (AHUNAM, FUN, sección DA, c. 18, exp. 464, ff. 07926-07927).
Imagen 3. Carlos J. Meneses

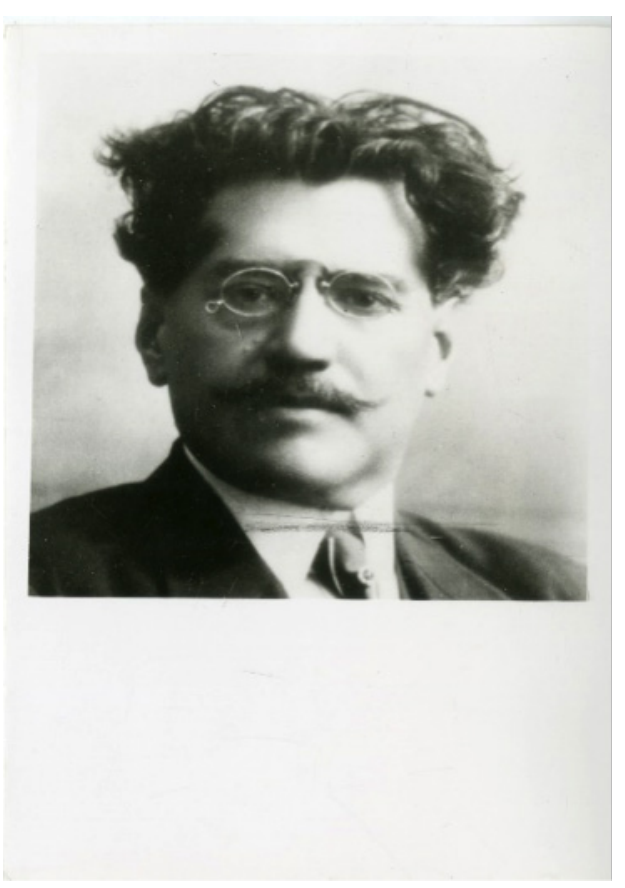

Fuente: Biblioteca Nacional, del Archivo de Iconoteca, Archivo de Expedientes.

\section{El plan de estudio y la dirección de orquesta}

En la etapa final del Conservatorio dentro de la Universidad, junto con la Secretaría de Educación Pública, se aprobó - en febrero de 1929 - el último plan de estudios del Conservatorio o Escuela Nacional de Música, Teatro y Danza. Este plan de estudios me atrevo a constituirlo como un elemento del

\footnotetext{
${ }^{23}$ Un año después, el 6 de abril de 1929, moriría el maestro Carlos J. Meneses. El 18 de abril de 1949, la Universidad Nacional, por iniciativa de la Dirección General de Difusión Cultural, decidió no pasar inadvertido el aniversario del maestro Meneses, celebrando un homenaje con la participación de la Orquesta de Cuerda de la Escuela Nacional de Música de la Universidad. El doctor Alfonso Pruneda presidió el homenaje, y en su discurso destacó la trayectoria y legado del maestro Meneses en el Conservatorio y sus discípulos: Pedro Ogazón, Alberto Villaseñor, Luis Moctezuma, Carlos Lozano, Carmen Munguía, Rafaela Parra, Alba Herrera y Ogazón, Otilia Ayala, Carlos del Castillo, entre muchos.

${ }^{24}$ La historiadora Olivia Moreno Gamboa (2014), presenta un ensayo muy interesante sobre el establecimiento musical de A. Wagner y Levien, fundado a mediados del siglo XIX en la ciudad de México. Éste se titula "Casa, centro y emporio del arte musical: la empresa alemana A. Wagner y Levien en México. 1851-1910". La empresa contaba con una fábrica de pianos, así como con una tienda de partituras e instrumentos de banda y orquesta. En mi tesis doctoral (2016: 129-132) publico un par de cartas enviadas en 1901 al ministro José Ives Limantour, brazo financiero del presidente Porfirio Díaz, por parte de A. Wagner y Levien para ser considerados en un concurso para la adquisición de un órgano en el Conservatorio Nacional de Música. La megalomanía de Limantour y su cercanía con Díaz fueron un punto estratégico en los inicios de esta empresa musical.
} 
proceso de titulación académica en la pertenencia del campo artístico de los músicos universitarios. En el artículo $1^{\circ}$ del plan de estudios, se enfatizó el objetivo principal de la institución musical, que consistía en la "enseñanza, difusión y cultivo del arte musical, teatral y coreográfico". Las carreras musicales que se impartieron se presentaron en el artículo $2^{\circ}$, las cuales eran "piano, órgano y canto llano, todos los instrumentos de orquesta sinfónica y banda militar, dirección de orquesta, composición y canto", así como también se siguieron incluyendo a las carreras de Teatro y Danza. Los requisitos para cursar los estudios musicales en el Conservatorio universitario se delinearon en los artículos $3^{\circ}$, y $4^{\circ}$, en donde se les exigía a los alumnos acreditar haber cursado la Instrucción Primaria Superior, así como no ser mayores a 21 años. Las carreras musicales se dividieron en dos grados, el Preparatorio y el Profesional (AHUNAM, FUN, sección DA, c. 31, exp. 892, f. 12552).

El grado Preparatorio se cursaba en los primeros tres años, y era obligatorio para todas las carreras. En el caso específico de los alumnos que optaban por la carrera de "Dirección de orquesta y composición", éstos debían seleccionar como instrumento - desde el primer año- el piano. La carrera de piano se cursaba en tres años de grado preparatorio y seis años de grado profesional, en este último se impartían las siguientes asignaturas: Primer año. Piano, Teoría Musical Superior (ler curso), Historia de la Música, Acústica, Francés e Inglés. Segundo año. Piano, Teoría Musical Superior $\left(2^{\circ}\right.$ curso), Historia de la Música ( $2^{\circ}$ curso), Conjuntos de Cámara u Orquesta, Francés e Inglés ( $2^{\circ}$ curso). Tercer año. Piano, Teoría Musical Superior (3er curso), Conjuntos de Cámara u Orquesta. Cuarto año. Piano, Conjuntos de Cámara u Orquesta. Quinto año. Piano, Conjuntos de Cámara u Orquesta, Prácticas individuales. Sexto año. Piano, Conjuntos de Cámara u Orquesta, Prácticas individuales. La especialización en Dirección de Orquesta se daba a partir del tercer año profesional, y simultáneamente con las asignaturas de la carrera de piano, los alumnos debían tomar un curso de la materia de Teoría de la Dirección de Orquesta, y tres cursos de Práctica de Dirección de Orquesta (AHUNAM, FUN, sección DA, c. 31, exp. 892, ff. 12553-12556).

\section{La Orquesta de Alumnos de la Facultad de Música}

La separación del Conservatorio de la Universidad provocó una reconfiguración del campo artístico de los músicos universitarios. Los elementos de pertenencia en la construcción de una identidad universitaria tuvieron que articularse, ahora, como "no" conservatoriana y acorde a la autonomía lograda tras el conflicto universitario. Muchos de estos elementos de pertenencia costaron a los músicos protagonistas, como el maestro Estanislao Mejía, ${ }^{25}$ tiempo, negociaciones y disputas para volver a consolidarlos; la situación económica de la Universidad se tornó delicada, y por lo tanto no sería fácil conseguir la subvención económica para la recién creada Orquesta de Alumnos de la Facultad de Música.

\footnotetext{
${ }^{25}$ El 26 de febrero de 1944, el maestro Estanislao Mejía envió a Don Rafael Carrasco Puente, jefe de la Hemeroteca Nacional, un retrato en fotografía y sus datos biográficos. Mejía, además de profesor de música, inició en el periodismo musical en 1920 en "Arte y Labor", órgano de la Unión Filarmónica de México; colaboró en el diario El Universal desde 1926 con motivo de la celebración del Primer Congreso Nacional de Música, hasta 1938, año en que renunció como director del Conservatorio Nacional de Música. De 1938 a 1940, escribió artículos semanarios en la revista semanal "Ilustrado". De 1940 a 1941, colaboró en el diario Novedades, y de julio de 1942, hasta la fecha de 1944, tenía a su cargo la dirección de Orientación musical, revista mensual de cultura artística y órgano del Ateneo Musical Mexicano.
} 


\section{Imagen 4. Estanislao Mejía}

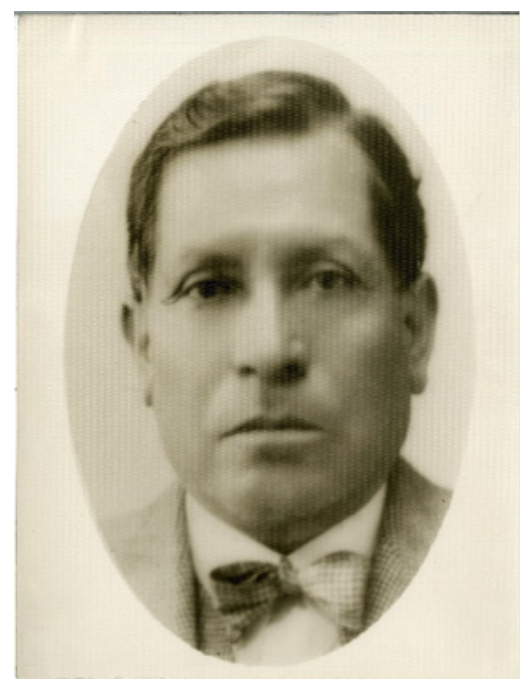

Fuente: Biblioteca Nacional, del Archivo de Iconoteca, Archivo de Expedientes.

En febrero de 1931, la Orquesta de Alumnos de la Facultad de Música logró contar con un reglamento, y se integraba por 40 alumnos, sin embargo, el panorama para la subvención económica de sus alumnos integrantes no fue nada alentador. Ante esta situación, el maestro Estanislao Mejía, como director de la Facultad de Música, dirigió un oficio en ese mes, al licenciado Ignacio García Téllez, rector de la UNAM:

Considerando que la Facultad de Música para cumplir debidamente su misión no sólo en la educación técnica y artística de sus alumnos sino en la que debe impartir al pueblo para despertar su emotividad y comprensión en las obras de arte, me permito solicitar de usted se sirva conceder a los alumnos que forman la orquesta del plantel una gratificación de diez pesos mensuales por alumno, ya que estos tienen necesidad de hacer gastos extraordinarios para la asistencia a los ensayos de orquesta así como la compra de útiles instrumentales" (ahunam, fun, sección da, c. 61, exp. 2091, f. 21849).

En esta misiva se puede palpar el carácter nacionalista de la misión de la Facultad de Música, haciendo énfasis en la relación de ésta, el pueblo y el arte, en otras palabras, la institución musical muestra su disposición a empatarse con los programas del gobierno posrevolucionario. El cierre de este oficio escrito por el maestro Estanislao destacó la importancia y su preocupación en la difusión del ambiente musical universitario:

Los institutos, escuelas y facultades universitarias, tienen necesidad de integrar en sus programas de exteriorización educacional números musicales cubiertos por elementos de esta Facultad, y este es otro de los motivos que reclaman la organización de la orquesta de alumnos, en la forma que esta Dirección propone y que como antes se ha dicho, no solo hará propaganda artística dentro de la Universidad, sino servirá para revelar los caracteres musicales de la época".

Eduardo Sánchez García, Tesorero de la UNAM, contestó con una negativa la solicitud de gratificación de 10 pesos mensuales para alumnos de la Orquesta de la Facultad de Música, argumentando que así lo había acordado la Comisión de Hacienda por no existir partida que pudiera reportar el gasto en el presupuesto del año corriente (AHUNAM, FUN, sección DA, c. 61, exp. 2091, f. 21851).

El 18 de noviembre de 1931, el maestro Estanislao Mejía entonces director de la Facultad de Música de la Universidad Nacional Autónoma, ${ }^{26}$ informó al secretario general de la Universidad, que el día 29 en el anfiteatro "Bolívar" tendría lugar el $5^{\circ}$ Concierto de la Orquesta Sinfónica de la Facultad de Música.

\footnotetext{
${ }^{26}$ En las hojas membretadas de los oficios aparece de manera fija el logotipo del escudo de la universidad y al pie de éste ya se muestra el título de "UNIVERSIDAD NACIONAL AUTÓNOMA".
} 
En dicha carta el maestro Mejía destacó la carencia de fondos para integrar los gastos que originaba el mantenimiento de la Orquesta, motivo por el cual el concierto se brindaría bajo la modalidad de paga, siendo el importe de las localidades a razón de $\$ 1.00$ para el público y $\$ 0.50$ para los estudiantes (AHUNAM, FUN, sección DA, c. 61, exp. 2092, f. 21852). Como se puede apreciar en el siguiente programa, el concierto se efectuó constando de 5 partes:

\section{Petite Suite. Claude Debussy (En bateu, Cor-} tége, Menuet y Ballet). Orquesta de la Facultad de Música.

II. Suite. Tomás Ponce Reyes (Preludio, Romanza y Scherzo). Orquesta de la Facultad de Música. ${ }^{27}$

III. Sansón y Dalila. Saint-Saens (Aria del primer acto). Canto Señora Fanny Anitúa. ${ }^{28}$

IV. Magnificat. Juan Sebastián Bach ("Magnificat anima mea" coros y orquesta, "Et exultavit" aria señora Fanny Anitúa, Fecitpotentiam, y Gloria). Coros y Orquesta de la Facultad de Música.

V. Sinfonía en Sol menor. Miguel C. Meza (Moderato assai- Allegro Molto, Andantino y Allegro). Orquesta de la Facultad de Música (AHUNAM, FUN, sección DA, c. 61, exp. 2092, f. 21853).

El 11 de diciembre del mismo año (AHUNAM, FUN, sección DA, c. 61, exp. 2092, ff.21855-21856), el maestro Estanislao Mejía envió al Secretario General de la Universidad Nacional una relación de los ingresos y egresos del $5^{\circ}$ Concierto de la Orquesta Sinfónica de la Facultad de Música. En la tabla 1 se puede apreciar de qué manera se destinaban los recursos económicos para la realización de una presentación de la orquesta sinfónica de alumnos, así como la cantidad que finalmente cubría el fondo del profesorado.

Tabla 1. Ingresos y egresos del $5^{\circ}$ concierto de la Orquesta Sinfónica de la Facultad de Música

\begin{tabular}{|c|c|c|c|}
\hline Concepto & Ingresos & Egresos & \\
\hline Efectivo recibido a la entrada por boletos & $\$ 194.00$ & & \\
\hline Contribución del profesorado de la primera quincena de noviembre & $\$ 56.50$ & & \\
\hline Gastos, anuncios, comisión, etc., según recibo & & $\$ 135.30$ & \\
\hline Pagado a la Unión Filarmónica a/c recibo $\$ 152.00$ & & $\$ 140.00$ & \\
\hline Pagado a la Banda Especial & & $\$ 45.00$ & \\
\hline Una canasta de flores a la señora Anitúa & & $\$ 9.00$ & \\
\hline Alquiler orquestación Sansón y Dalila & & $\$ 8.00$ & \\
\hline Tres sellos de goma contraseña para los conciertos & & $\$ 5.00$ & \\
\hline Vales por diversos acarreos para los ensayos & & $\$ 3.50$ & \\
\hline Alquiler bombo y platillos & & $\$ 2.00$ & \\
\hline Total & $\$ 250.50$ & $\$ 347.80$ & \\
\hline Déficit que ha sido cubierto con el fondo del profesorado & & & $\$ 97.30$ \\
\hline
\end{tabular}

Fuente: elaboración propia con base al documento del AHUNAM, FUN, sección DA, c. 61, exp. 2092, f. 21856.

\footnotetext{
${ }^{27}$ Los músicos Miguel C. Meza y Tomás Ponce Reyes, figuran en el programa y además son alumnos del último año de la carrera de composición de la Facultad.

${ }^{28}$ La famosa mezzosoprano fue invitada por su simpatía con profesores y músicos de la Orquesta de la Facultad de Música. Fanny Anitúa Yáñez (1887-1968), originaria del estado de Durango, fue becada por el gobierno estatal para estudiar en el Conservatorio Nacional de Música. El presidente Díaz subsidió sus estudios en Roma en la Academia de Aristide Francescchetti. Cantante de gran éxito en escenarios como el Teatro Nazionale de Roma, el Teatro de Santa María Alla Scala de Milán, el Teatro Colón de Buenos Aires, entre otros.
} 
El programa del $5^{\circ}$ Concierto de la Orquesta de la Facultad de Música, así como la lista de ingresos y egresos de su operación, nos arroja distintos elementos para continuar estudiando el campo artístico: qué tipo de música sinfónica se interpretaba, el nivel de su complejidad, cómo se impulsaba a los jóvenes compositores mexicanos, cuáles eran los recintos teatrales con los cuales contaba la universidad, cómo se reforzaba la orquesta de alumnos para ejecutar determinadas obras, y finalmente conocer cuál era el costo total de un concierto o recital. Para el maestro Estanislao Mejía era vital conseguir la subvención económica, como un elemento de consolidación en la relación entre la Universidad, el pueblo y el arte, y también, como una especie de reivindicación de esos logros con los cuales llegaron a contar las agrupaciones instrumentales musicales - Orquesta de Alumnos y Agrupación Universitaria de Música de Cámara- cuando el Conservatorio estuvo en el seno de la Universidad.

\section{Conclusiones}

Los músicos mexicanos que se formaron en el Conservatorio de Música, no sólo se erigieron como los destinatarios titulares de la alta cultura para acercarla a las capas populares; sino además tuvieron que fortalecer su identidad como músicos de la Universidad Nacional, articulando una serie de elementos de pertenencia que fueron conformando propiedades específicas en el campo artístico. Este artículo no solo hace una revisión y caracterización histórica de la fundación del Conservatorio y su estadía en las arterías de la Universidad, así como de su orquesta de Alumnos, en el contexto del nacionalismo de los gobiernos posrevolucionarios; sino pretende ir más allá, al articular y cruzar las fuentes bibliográficas y hemerográficas con una serie de documentos inéditos del Archivo Histórico de la Universidad Nacional de Autónoma de México, en un análisis sociológico que finalmente se posiciona en el ámbito artístico y pedagógico.

Cumpliendo con el objetivo principal de este artículo, y respondiendo a las interrogantes planteadas al inicio de éste, se lograron identificar los componentes de pertenencia que conformaron la identidad de los músicos del conservatorio universitario en el campo artístico, de acuerdo con los conceptos de Bourdieu: la subvención económica recibida por la Orquesta de Alumnos del Conservatorio, dirigida por el maestro Silvestre Revueltas, y la Agrupación Universitaria de Música de Cámara, dirigida por el maestro Carlos J. Meneses; el impulso de programas de concierto a través de la labor de difusión artística del Departamento de Extensión Universitaria; los reconocimientos - a manera de homenaje en vida - como el dedicado al maestro Carlos J. Meneses, y el plan de estudios para la carrera de piano con especialización en dirección de orquesta, como parte del proceso de titulación.

El vínculo educación-cultura, sellado en el vasconcelismo, permeó el campo artístico de los músicos; los documentos revisados para este estudio nos muestran el peso específico en la relación entre la Universidad y la Secretaría de Educación Pública, entre la educación y la investigación artística, como sucedió en el caso de la elaboración y aprobación de los planes de estudio. En el Plan General de Trabajo del Departamento de Extensión Universitaria predominó la "labor social", es decir, el compromiso de la educación superior con los programas posrevolucionarios. La difusión artística de los músicos del conservatorio universitario no solo integró la participación de la iniciativa privada y personalidades externas a la institución, sino que ésta llegó a diversos públicos, desde niños hasta trabajadores obreros. El legado del vasconcelismo alcanzó a todas las manifestaciones artísticas, puesto que nuestro país, ante un mundo que emulaba "modas", ${ }^{29}$ buscaba

${ }^{29}$ El historiador John Lukacs, en su obra El siglo XX (2015:14), encuentra dos fenómenos globales de largo alcance en las décadas de 
redescubrir su propia vocación cultural, "pero por lo que lucha Vasconcelos es por lograr el advenimiento de toda una concepción nueva de las relaciones entre el productor literario y artístico y el pueblo, al tiempo que se esfuerza por preservar ciertos valores, ciertos elementos, ciertos rasgos del folclor nacional, y de dar acceso al arte y a la cultura a los estratos sociales privados de él durante siglos" (Fell, 2009: 14).

La separación del Conservatorio de Música de la Universidad Nacional puede tener muchas lecturas de interpretación, y éstas pueden apuntar al músico Carlos Chávez como principal artífice de dicha escisión; sin embargo, debemos comprender las disputas internas como parte de la naturaleza misma del campo artístico, y demás campos, como bien señala Bourdieu al desarrollar esta teoría. El poeta y diplomático José Gorostiza escribió un breve artículo denominado "Carlos Chávez como agitador" en su sección "Torre de señales", y resumió con gran acierto la personalidad de este músico mexicano:

Piénsese ahora que Carlos Chávez, día a día, minuto a minuto, no sólo como director de la Orquesta Sinfónica - cuya sola existencia en México es casi un milagro - sino al frente del Conservatorio Nacional, celebra acuerdos, contesta correspondencia, dirige ensayos, publica una revista de conferencias, escribe artículos, ataca, se defiende, coordina, arrastra y atropella y se verá que si lo más probable es que no consiga realizar mucho - como todo agitadorconseguirá por lo menos hacerse añicos contra todos los obstáculos, para que otros cimenten el edificio musical de México sobre las ruinas de un Carlos Chávez demolido (El Ilustrado, 27/XI/1930: 8).

1920: uno, que la población blanca deja progresivamente de emigrar y establecerse en otros continentes, y segundo, la expansión internacional del idioma inglés, reemplazando al idioma francés como favorito de las clases altas. El cine y la música estadounidense se contaban entre las cosas que el mundo quería emular. En esta misma década el género musical del jazz invadió a México, e incluso el sindicato filarmónico de músicos llegó a dividirse en dos grupos, los jazzistas y los clásicos. 


\section{Referencias}

Acosta Romero, Miguel (1973), Teoría General del Derecho Administrativo, México, Porrúa.

Aguirre Lora, María Esther (2015), "Músicos en pos de una casa universitaria”, en María Esther Aguirre Lora (coord.), Rememorar los derroteros. La impronta de la formación artística en la UNAM, México, UNAM-IISUE/Bonilla Artigas Editores, pp. 75-111.

Aguirre Lora, María Esther (2006), Memoria en el tiempo. La Escuela Nacional de Música de la UNAM (ca. 1929-1945) [Memoria Versión Multimedia], México, Dirección General de Asuntos del Personal Académico de la UNAM-Centro de Estudios sobre la UniversidadEscuela Nacional de Música-UNAM.

Aguirre Lora, María Esther (2008), Preludio y Fuga. Historias trashumantes de la Escuela Nacional de Música de la UNAM, México, Instituto de Investigaciones sobre la Universidad y la Educación-UNAM-Plaza y Valdés

Álvarez, Lucía (2014), La música, el Dionisios vivo, México, Arteletra/Colofón.

Beristáin Cardoso, José Angel (2016), “Nacionalismo y política cultural. Creación y proceso institucional de una orquesta sinfónica nacional en México (18821947)", Tesis inédita de doctorado, México, Escuela Nacional de Antropología e Historia.

Beristáin Cardoso, José Angel (2018), "Política cultural en México. De la educación al entretenimiento", en Javier Tobar, Alberto Zárate, y Javier Grosso (comps.), El patrimonio cultural en tiempos globales, Popayán Colombia, Editorial Universidad del Cauca, pp. 201220.

Bourdieu, Pierre (2011), Capital cultural, escuela y espacio social, México, Siglo XXI editores.

Bourdieu, Pierre (2009), Homo academicus, México, Siglo XXI editores.

Bourdieu, Pierre (2002a), La distinción. Criterio y bases sociales del gusto, México, Taurus.

Bourdieu, Pierre (2002b), Campo de poder, campo intelectual, Tucumán, Editorial Montressor.

Bourdieu, Pierre (1995a), Las reglas del arte, México,
Editorial Anagrama.

Bourdieu, Pierre (1995b), Respuestas por una antropología reflexiva, México, Editorial Grijalbo.

Bourdieu, Pierre (1990), Sociología y cultura, México, Editorial Grijalbo.

Carmona, Gloria (2001), De la Real Universidad de México a la UNAM. 450 años. Suplementos de los 450 años de la Universidad de México, México, UNAM.

Carmona, Gloria (comp.) (1997), Carlos Chávez. Obras I. Escritos periodísticos (1916-1939), México, El Colegio Nacional.

Fell, Claude (2009), José Vasconcelos: los años del águila (19201925). Educación, cultura e iberoamericanismo en el México posrevolucionario, México, UNAM.

Garcíadiego, Javier (1996), Rudos contra científicos. La Universidad Nacional durante la Revolución Mexicana, México, El Colegio de México/CESU-UNAM.

Herrera y Ogazón, Alba (1917), El arte musical en México, México, Departamento Editorial de la Dirección General de las Bellas Artes.

Loyo, Engracia (2010), "La educación del pueblo", en Dorothy Tanck de Estrada (coord.), La educación en México, México, El Colegio de México, pp. 154-187.

Lukacs, John (2015), Historia mínima del siglo XX, México, El Colegio de México.

Marsiske Schulte, Renate (2016), "La Universidad Nacional: creación, autonomía y marco normativo”, en Hugo Casanova Cardiel (coord.), La UNAM y su historia. Una mirada actual, México, IISUE- UNAM [Historia de la Educación], pp. 151-189.

Miranda, Ricardo y Aurelio Tello (2011), "La música en Latinoamérica", en Mercedes de Vega (coord.), La búsqueda perpetua: lo propio y lo universal de la cultura latinoamericana, México, Dirección General del Acervo Histórico Diplomático, Secretaría de Relaciones Exteriores, pp. 53-68.

Moreno Gamboa, Olivia (2014), "Casa, centro y emporio del arte musical: la empresa alemana A. Wagner y Levien en México. 1851-1910”, en Laura Suárez de la Torre (coord.), Los papeles para Euterpe. La música en la ciudad de México desde la historia cultural. Siglo XIX, México, 
Instituto de Investigaciones Dr. José María Luis Mora, pp. 143-168.

Moreno Gamboa, Olivia (2009), Una cultura en movimiento. La prensa musical de la Ciudad de México (1860-1910), México, UNAM/IHAH.

Night, Alan (2015), La revolución cósmica. Utopias, regiones y resultados, México 1910-1940, México, Fondo de Cultura Económica.

Pérez Montfort, Ricardo (2015), "Introducción. Las claves: dos siglos de cultura mexicana", en Ricardo Pérez Montfort (coord.), México contemporáneo 18082014. La Cultura, México, El Colegio de México/ Fundación Mapfre/FGE, pp. 11-30.

Pérez Montfort, Ricardo (1999), "Un nacionalismo sin nación aparente (La fabricación de lo "típico" mexicano 1920-1950)", en Política y Cultura, núm. 12, México, Universidad Autónoma Metropolitana Unidad Xochimilco, pp. 177-193.

Pérez Vejo, Tomás (1999), Nación, identidad nacional y otros mitos nacionalistas, España, Ediciones Nobel.

Ríos Zuñiga, Rosalina (coord.) (2015), Instituciones modernas de educación superior. Institutos científicos y literarios de México, siglos XIX y XX, México, UNAM-IISUE/Bonilla Artigas Editores.

Rodríguez Morales, Leopoldo (2012), El campo del constructor en el siglo XIX. De la certificación institucional a la esfera pública en la Ciudad de México, México, INAH.

Tovar y de Teresa, Rafael (1994), Modernización y política cultural, México, Fondo de Cultura Económica.

Vaughan, Mary Kay (2001), La política cultural en la Revolución. Maestros, campesinos y escuelas en México, 19301940, México, Fondo de Cultura Económica.

Velazco, Jorge (1988), La música por dentro, México, UNAM. Woldenberg, José (2008), "Autonomía universitaria:
Esbozo histórico y significado", en Universidades, núm. 36, México, Unión de Universidades de América Latina y el Caribe, pp. 61-64.

Zanolli Fabila, Betty Luis de María Auxiliadora (1997), "La profesionalización de la enseñanza musical en México. El Conservatorio Nacional de Música (18661996)", vol. I y II, Tesis inédita de doctorado, México, UNAM.

\section{Fuentes documentales}

Archivo Histórico de la UNAM (AHUNAM).

Fondo Universidad Nacional, sección Departamento de Administración.

Biblioteca de las Artes, CENART.

Fondo Gerónimo Baqueiro Foster.

Biblioteca Nacional, del Archivo de Iconoteca, Archivo de Expedientes.

\section{Fuentes Hemerográficas}

Boletín de la Secretaría de Instrucción Pública, 1915, 1916.

El Nacional, 1917, 1949.

El Universal, 1929.

Gaceta UNAM, 19 de noviembre de 2001.

Informe del Departamento de Extensión Universitaria, Universidad Nacional, 1929.

Memoria de la Sociedad Filarmónica Mexicana, 1868.

\section{Artículos en publicaciones periódicas}

Baqueiro Foster, Gerónimo, "Carlos J. Meneses, El mundo de la música", Suplemento de El Nacional, 27 de marzo de 1949.

Reyes, Víctor, "La música en México y en el extranjero. La música y los músicos entre bastidores", El Ilustrado, 18 de noviembre de 1937.

Cómo citar este artículo:

Beristáin-Cardoso, José-Ángel (2019), "La Orquesta del Conservatorio en el seno de la Universidad Nacional (1917-1929)", en Revista Iberoamericana de Educación Superior (RIES), México, UNAM-IISUE/Universia, vol. X, Núm. 27, pp. 93-113, DOI: dx.doi.org/10.22201/iisue.20072872e.2019.27.342 [consulta: fecha de última consulta]. 